\title{
RECURSOS EDUCACIONAIS ABERTOS E AS TECNOLOGIAS DIGITAIS DE INFORMAÇÃO E COMUNICAÇÃO: FORMAÇÃO E PRÁXIS EM ESCOLAS RIBEIRINHAS
}

OPEN EDUCATIONAL RESOURCES AND DIGITAL INFORMATION AND COMMUNICATION TECHNOLOGIES:

TRAINING AND PRAXIS IN RIBEIRINHAS SCHOOLS

\author{
RECURSOS EDUCATIVOS ABIERTOS Y TECNOLOGÍAS DIGITALES DE INFORMACIÓN Y \\ COMUNICACIÓN:
}

FORMACIÓN Y PRAXIS EN ESCUELAS RIBEIRINASTÍTULO EM ESPANHOL

Lucila Maria Pesce de Oliveira ${ }^{1}$

Doriedson Alves de Almeida ${ }^{2}$

Ana Pâmela Guimarães Pereira ${ }^{3}$

RESUMO

Submetido em: 30/09/2020 - Aceito em: 14/12/2020 - Publicado em: 25/01/2021

${ }^{1}$ Pós-Doutora em Filosofia e História da Educação, pela Universidade Estadual de Campinas (UNICAMP); Doutora e Mestre em Educação: Currículo, pela Pontifícia Universidade Católica de São Paulo (PUC/SP); Bacharel e Licenciada em Letras - Português e Inglês, pela Universidade Presbiteriana Mackenzie (UPM). Professora Associada do Departamento de Educação da Universidade Federal de São Paulo (UNIFESP); professora credenciada no Programa de Pós-Graduação em Educação da UNIFESP.Líder do Grupo de Pesquisa LEC: Linguagem, Educação e Cibercultura. Vice coordenadora do GT 16 da ANPEd Membro das seguintes redes internacionais de pesquisa: REPEM (Rede de Pesquisas em Educação e Mídia, Unirio), Red Estrado (Rede Latino-Americana de Estudos sobre Trabalho Docente), COLEARN (Collaborative Open Learning, The Open University, vinculada à Responsible Research and Innovation - RRI).

${ }^{2}$ Doutor em Educação pelo PPGE - FACED-UFBA; Mestre em Educação PPGE/UFES; Bacharel em Ciências Contábeis pela FACEC - Faculdade de Ciências Econômicas de Colatina; Pós-graduado em Informática aplicada à educação pela PUC-MG, Engenharia da Informação e Orientação em EAD pela UFES. Professor no Programa de Pós-graduação em Educação - PPGE do ICED-UFOPA e no Centro de Formação Interdisciplinar - CFI - UFOPA. Consultor em projetos para uso das TIC em processos de ensino e aprendizagem, gestão em educação e serviço público.

${ }^{3}$ Mestra em Educação pela Universidade Federal do Oeste do Pará (Ufopa). Especialista em Coordenação Pedagógica (Ufopa). Graduada em Licenciatura Plena em Pedagogia (Ufpa). Docente pedagógico na Universidade Paulista de Santarém; Técnica Administrativa em educação na Universidade Federal do Oeste do Pará. E membro colaborador no grupo oficiber - Oficinas em cibercultura, Ufopa. 
Este artigo trata do papel dos Recursos Educacionais Abertos (REA), um movimento que se empenha em promover acesso, uso e reuso de materiais educacionais no contexto da formação e práxis de escolas ribeirinhas da região do baixo Amazonas. Através das perspectivas de um grupo de profissionais de educação no campo da Amazônia paraense, este estudo objetivou examinar os limites e as possibilidades do uso dos REA como Tecnologias Digitais da Informação e Comunicação (TDIC) na promoção de práticas colaborativas, na formação e práxis em escolas ribeirinhas. O estudo parte da premissa de que os professores têm papel imprescindível na promoção de reflexões e atitudes praxiológicas apesar das estruturas e redes instituídas nas unidades federativas, pois não há rede de ensino sem atuação instituinte, colaboração, criação comum e compartilhamento. O artigo também adverte para o fato de que os conceitos e benefícios dos REA para a educação permanecem restritos a especialistas sobre o tema ou atrelados às diferentes tecnocracias. A metodologia deste trabalho valeu-se da produção de dados, ao longo de sessões de conversa, para um estudo descritivo e crítico da potencialidade didática dos REA. A análise dos dados revela desafios a serem enfrentados, dentre os quais a problemática de políticas públicas educacionais no que se refere à temporalidade e à continuidade dos programas e iniciativas de TDIC na região do baixo Amazonas. Os achados da pesquisa sugerem a existência de coletivos educacionais que possuem criatividade para lidar com insuficiências técnicas e entraves burocráticos, porém demandam políticas públicas voltadas para a melhoria e a instituição de outras práxis.

PALAVRAS-CHAVE: Recursos Educacionais Abertos. Tecnologias Digitais da Informação e Comunicação. Práxis escolar ribeirinha. Políticas públicas.

\section{ABSTRACT}

This article deals with the role of Open Educational Resources (OER), a movement that strives to promote access, use and reuse of educational materials in the context of the training and praxis of riverside schools in the lower Amazon region. Through the perspectives of a group of education professionals in the field of Pará's Amazon, this study aimed to examine the limits and possibilities of using OER as Digital Information and Communication Technologies (TDIC) in the promotion of collaborative practices, in training and praxis in riverside schools. The study starts from the premise that teachers have an essential role in promoting reflections and praxiological attitudes despite the structures and networks established in the federative units, as there is no teaching network without instituting action, collaboration, common creation and sharing. The article also warns that the concepts and benefits of OER for education remain restricted to specialists on the topic or linked to different technocracies. The methodology of this work used data production, during conversation sessions, for a descriptive and critical study of the didactic potential of OER. The analysis of the data reveals challenges to be faced, among which the issue of educational public policies with regard to the temporality and continuity of DICT programs and initiatives in the lower Amazon region. The research findings suggest the existence of educational collectives that have the creativity to deal with technical shortcomings and bureaucratic obstacles, but they demand public policies aimed at the improvement and the institution of other praxis.

KEYWORDS: Open Educational Resources. Digital information and communication technologies. Riverside schools práxis. Public policies.

\section{RESUMEN}

Este artículo trata sobre el rol de los Recursos Educativos Abiertos (REA), movimiento que busca promover el acceso, uso y reutilización de materiales educativos en el contexto de la formación y praxis de las escuelas ribereñas de la región baja amazónica. A través de las perspectivas de un grupo de profesionales de la educación en el campo de la Amazonía de Pará, este estudio tuvo como objetivo examinar los límites y posibilidades del uso de los REA como Tecnologías de Información y Comunicación Digitales (TDIC) en la promoción de prácticas colaborativas, en la formación y praxis en escuelas ribereñas. El estudio parte de la premisa de que el docente tiene un papel fundamental en la promoción de reflexiones y actitudes praxiológicas a pesar de las 
estructuras y redes establecidas en las unidades federativas, ya que no hay red docente sin instituir acción, colaboración, creación común y compartir. El artículo también advierte que los conceptos y beneficios de los REA para la educación quedan restringidos a especialistas en el tema o vinculados a diferentes tecnocracias. La metodología de este trabajo utilizó la producción de datos, durante las sesiones de conversación, para un estudio descriptivo y crítico del potencial didáctico de los REA. El análisis de los datos revela desafíos a enfrentar, entre los que destaca el tema de las políticas públicas educativas en cuanto a la temporalidad y continuidad de los programas e iniciativas de TICD en la región de la baja Amazonía. Los hallazgos de la investigación sugieren la existencia de colectivos educativos que tienen la creatividad para enfrentar las deficiencias técnicas y los obstáculos burocráticos, pero demandan políticas públicas orientadas al mejoramiento y la institución de otras praxis.

PALABRAS CLAVE: Recursos educativos abiertos. Tecnologías Digitales de la información y la comunicación. Praxis de escuelas de ribera. Políticas públicas.

\section{INTRODUÇÃO}

A sociedade atual ergue-se em meio a constantes novidades tecnológicas e à escola compete, como seguimento social, o papel de desenvolver novas propostas educacionais vinculadas às Tecnologias Digitais da Informação e Comunicação (TDIC). Logo, produzir novos saberes de forma inovadora, muitas vezes, conduz os atores educacionais a supor que precisam ser gênios na competência digital. Em verdade, ao contrário das suposições, deve-se procurar aprender a caminhar ao lado dessas evoluções tecnológicas, percebendo que as mudanças existem e tentando integrá-las às práticas educativas de modo a aproveitar da melhor forma possível os ambientes educacionais presenciais e virtuais.

Contudo, para alcançar tais interpretações, é preciso investir, potencializar processos, incentivar pesquisas que apoiem um conjunto de propostas com algum enfoque que sirva de guia e de base para uma educação emancipadora. É nesse contexto que emerge a relevância dos Recursos Educacionais Abertos (REA), por integrarem um movimento de potencialidades, através do uso das TDIC, para que os professores venham a se tornar atores em rede, produzindo conhecimento de acordo com sua realidade escolar.

Este trabalho se ocupou de examinar as potencialidades dos REA para o exercício de práticas 
colaborativas. Tal investigação busca transcender as discussões acadêmicas das regiões brasileiras mais centrais, almejando alcançar os professores da Amazônia, uma região singular e de mosaico cultural. Este artigo direciona-se, notadamente, aos professores das escolas ribeirinhas da Amazônia Paraense.

Vale, portanto, destacar que este texto objetiva discutir REA como opção de inovação, elaboração própria ao professor que se faz autor, considerando a singularidade da região amazônica, produzindo material, possibilidade da teoria se lançar na prática, ressignificando aprendizagem juntamente com o alunado.

Para alcançar esse objetivo, atuou metodologicamente na abordagem qualitativa por ser esta, segundo Lüdke (1986), rica em dados descritivos, por ter um plano aberto e flexível e por focalizar a realidade de forma complexa e contextualizada, sendo, dessa forma, a mais adequada para fornecer os subsídios necessários ao estudo proposto. Salientando que no início desse estudo a internet era quase inexistente, contando somente com a demasia de aparatos tecnológicos do ProInfo, foi necessário desenvolver um esforço para a aplicação da pesquisa, pois o estudo de caso foi a forma assumida em seu procedimento.

Notabiliza-se que as discussões deste estudo descendem da Dissertação de Mestrado em Educação, intitulada "Recursos Educacionais Abertos: contextualização da Tecnologia da Informação e Comunicação em uma escola na comunidade ribeirinha do município de Juruti/PA".

\section{RECURSOS EDUCACIONAIS ABERTOS E O PROFESSOR}

Os REA, diferentemente dos recursos educacionais comuns que são de conhecimento geral e caracterizados como plano de aula, livros didáticos, material curricular e outros, têm dois princípios: licença aberta de uso e princípio técnico. A licença aberta de uso refere-se à 
possibilidade de as pessoas fazerem do material que têm acesso um uso mais condizente com a sua prática, sem correr o risco de infringir os direitos autorais. O princípio técnico, na vertente educacional, refere-se à possibilidade de o professor criar aulas e materiais de modo autoral, situando-se, pois, como colaborador no processo educacional para além do status de consumidor do elaborado nos grandes centros privilegiados (PRETTO, 2012).

Por certo que a situação atual do movimento em prol dos REA e de seus licenciamentos ainda se mantém desconhecida pela maioria dos profissionais de educação. A despeito das afirmativas de ações colaborativas de advogados para articulação legal de licença, artistas que criam materiais e disponibilizam na rede para uso em sala de aula, secretarias educacionais que produzem em parceria com pesquisadores cartilhas de divulgação dos REA, colaboradores da disseminação desses recursos, no campo educacional, ainda há um longo caminho a ser trilhado. Porém, apesar do conhecimento ainda um tanto insipiente de REA pelos professores, é preciso empenhar essa bandeira, garantir que professores possam conhecer as possibilidades dos REA para promover uma profícua discussão na escola em prol de práticas educativas autorais e coautorais por professores e estudantes.

Na perspectiva de produção autoral, os REA possibilitam ao professor criar maneiras de produzir e publicar seus próprios materiais didáticos. Ao incorporar os REA às suas práticas pedagógicas e ao compartilhar suas experiências e saberes, os professores podem superar o discurso hegemônico de utilização das TDIC sob o viés instrumental (PESCE, 2013) para mobilizar seus pares professores e seus estudantes à plena vivência da cultura digital nas escolas (BONILLA, 2010).

Essas possibilidades advêm das cinco características primordiais dos REA, conforme demonstrado na figura a seguir: 


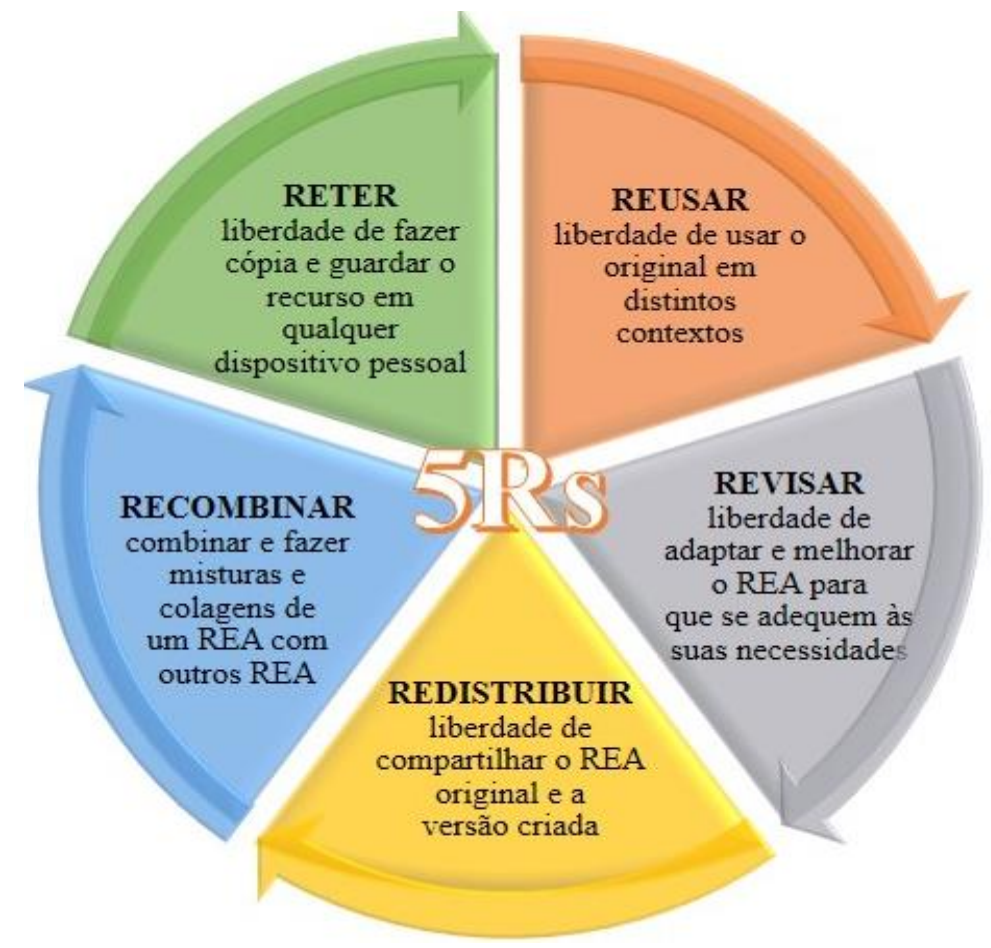

Figura 1. Os 5R dos REA

Fonte: Fettermann (2014)

Em convergência com Pesce (2013) e Pretto (2012), destaca-se que a escola deve ir além do espaço de consumo de informações. Para alcançar um protagonismo, observa-se que há necessidade de que os REA sejam contextualizados à realidade dos professores e dos estudantes, situando-os como produtores de conhecimento e cultura. Assim sendo, atenta-se para a relevância das aproximações entre REA, docência, pesquisa e da recusa à retirada da autonomia do docente. Sob a bandeira do professor autor, articulado ao movimento REA, introduz-se interação e troca. Para Pretto (2010), a rede poderia estabelecer e fortalecer:

Interação e troca entre sujeitos. Interação e troca entre produtos culturais. Recombinagem. Remixagem. Nova produção e diálogo permanente com o instituído, produzindo-se, a partir daí, novos produtos, novas culturas e novos conhecimentos. Tudo no plural. Com isso, temos a possibilidade de retomar o papel de liderança acadêmica do professor, que, em conjunto com os alunos, no coletivo e individualmente, passam a interagir de forma intensa com esse labirinto de possibilidades. (PRETTO, 2010, p. 314) 
O indivíduo da escola é somente consumidor? Quanto à internet, quais são os limites para o comércio e a democracia? Essas indagações preditas por Paulo Freire em 1984 para a Revista BITS no artigo “A máquina está a serviço de quem?” põem às claras a ideia de que o artefato tecnológico é carregado de um caráter político e ideológico. O uso de REA e de todo e qualquer dispositivo tecnológico deve ser eivado de criticidade em sala de aula; caso contrário, conforme destaca Freire (1984), haverá a "educação bancária": depósito de informações que na construção de aprendizagem em meio à tecnologia representa somente treinamento para a formação em massa para ingressar no mercado de trabalho.

Da proteção da liberdade, da criação e da recriação inerentes ao movimento REA, há de se explicitar o sentido de digital e social. Quanto a isso, Léa Fagundes (2014), professora da Universidade Federal do Rio Grande do Sul e uma das defensoras do software livre, sempre considerou o computador como mais que um recurso pedagógico, cabendo ao professor explorar com seu alunado o dito novo, não bastando somente garantir o acesso à tecnologia, mas também a apropriação dela na resolução de problemas.

\section{CONEXÃO CONTEMPORÂNEA NA AMAZÔNIA}

$\mathrm{Na}$ Amazônia paraense, a educação possui desafios que se refletem nas iniciativas e incentivos por parte do poder público, bem como nas condições de vida e de acesso dos estudantes que nela habitam. Somando-se a esse contexto, há uma sociedade envolvida cada vez mais com o uso de tecnologias digitais da informação e comunicação (TDIC), criando espaços de troca de conhecimento adquirido fora da escola, graças aos avanços tecnológicos que reinventam novas relações com o saber. Sendo assim, nessa equação há de se vislumbrar um futuro em que essa região empreenda a busca por novas alternativas formativas.

Para Moura (2012), considerando essa urgência, bem como as dificuldades relativas à 
disponibilidade de recursos tecnológicos adequados às necessidades da região, é importante incluir efetivamente a população da Amazônia em um contexto de possibilidades e potencialidades advindas das TDIC para a diversidade cultural e para a emancipação das subjetividades e dos saberes.

É usual a errônea ideia de que nessa parte do território brasileiro se recebem investimentos desproporcionais à extensão do território e às suas peculiaridades no que se refere às demandas para a formação de professores e para a infraestrutura das escolas. No interior amazônico, é comum que crianças, estudantes e profissionais da educação naveguem em barcos por 3 a 4 horas para ao espaço escolar. O mais próximo é sempre distante. O desenvolvimento da cultura e da singularidade dessa região brasileira ergue-se em meio a grandes distâncias sociais e geográficas. Por essa razão, o desejo por melhorias nesse contexto educacional não deve anular as múltiplas culturas da região amazônica, mas integrar a população amazônica com as demais populações do país.

Pensar em atividades que integrem a Amazônia brasileira significa ir além do comportamento apontado por Bonilla e Oliveira (2011). Para os autores, em decorrência de propostas emergenciais de Inclusão Digital (ID), acaba-se fazendo intervenções que se restringem a possibilitar que o indivíduo possua acesso aos computadores. Contudo, a ID ocorre quando o sujeito, através do acesso aos dispositivos tecnológico, exerce sua cidadania. Para isso, é necessária a compreensão do conceito de democratização da informática (a quem se destina) e a percepção de que a ID visa a melhorar as condições de vida de uma determinada comunidade.

Bonilla (2005) ainda ressalta que o processo de inclusão digital deve erguer-se em meio a maneiras de escapar da perspectiva economicista. Para que de fato os sujeitos sociais estejam incluídos, deve-se oportunizar-lhes maneiras para que participem, questionem, produzam e decidam de modo a transformar a dinâmica social em todas as suas instâncias. 
Para se enfrentar os indicadores de ID, não somente com soluções paliativas e compensatórias, lança-se a experiência reportada por Moura (2012) sobre os projetos de extensão universitária mediante os quais o acesso às tecnologias, por meio de ações criativas, pode transformar o cenário de marginalização de uma região socialmente vulnerável. Em Curralinho, no Marajó/PA, por exemplo, um grupo de estudantes de Engenharia da Computação da Universidade Federal do Pará (UFPA) instalou estações de trabalho, cujos computadores funcionam com energia solar, já que não havia energia elétrica. Também não havia infraestrutura de telecomunicações, nada de telefones ou conexões à internet, sabe-se que a conexão via satélite tem alto valor, mas o projeto de extensão universitária supracitado permitiu que todos os recursos usados se tornassem autossustentáveis.

Amparado em Castells (2007), Moura (2012), destaca que o uso progressivo das possibilidades interativas entre os povos, por meio das mídias digitais, possibilita a diminuição das diferenças, por integrar os sujeitos sociais dessas regiões ao universo mais amplo em que estão inseridos.

O uso de tecnologia pela população amazônica é decorrente de políticas públicas voltadas à integração das TDIC à educação a partir dos programas governamentais da década de 1990 (SANTANA et al., 2012, p. 33). A obra denominada "Livro Verde do Programa Sociedade da Informação", lançada em 2000, explica que quando o Brasil incorporou em sua agenda política a universalização do acesso às TDIC para criar condições de inserção no mercado mundial, o país demonstrava atraso nas políticas de conexão e desigualdade no acesso às TDIC nas diferentes classes sociais. Infelizmente, após duas décadas, muitos aspectos permanecem. Em outros termos, embora fortemente propagados, os programas de TDIC e educação no Brasil e na Amazônia ainda têm um longo caminho a ser trilhado para que se efetive a integração das TDIC nas práticas sociais exercidas na Amazônia paraense. Os formuladores de tais políticas públicas põem em risco os objetivos dos aludidos programas de ID quando não incluem a região e os atores que farão parte desse processo na escola. A Amazônia deve ser pensada a partir do seu contexto, das suas circunstâncias. Daí a 
importância de que tais políticas públicas priorizem as comunidades que encontram dificuldade nesse processo de ID, reconhecendo a diversidade geográfica e cultural inerente a essa região brasileira. Sob a alegação de tratar a todos igualmente, o Estado acaba por acirrar as desigualdades por viabilizar poucos recursos para quem mais precisa.

\section{MOVIMENTO METODOLÓGICO}

A partir da indagação "quais são as possibilidades do uso dos REA na didática docente, considerando os aspectos de uma escola do campo na Amazônia paraense?”, o estudo relatado no presente artigo contou com um grupo de professores de uma escola do campo de uma comunidade ribeirinha no município de Juruti/PA. Essa escola foi escolhida em razão de já ter feito parte de ações extensionistas ligadas ao Proinfo Rural, com vigência de dezembro de 2012 a abril de 2013. Ao utilizar software livre, o projeto auferiu liberdade ao usuário para executar, acessar e modificar o código fonte e redistribuir cópias. Tal vivência permitiu aos professores da escola em tela trabalhar com conceitos introdutórios no campo dos REA nessas ações extensionistas.

Considerando dados da ação anterior do projeto de extensão, houve aplicação de questionário para os professores envolvidos para compreender o sentido e o significado que os 13 professores auferiram à ação extensionista em tela. Houve encontros com esses docentes, com socialização e partilha de leituras pelos sujeitos. Em tais encontros, os professores puderam compartilhar experiências, dificuldades e avanços no processo vivenciado conjuntamente.

Nessa lógica, e inicialmente por haver restrições de acesso à internet, o trabalho assume uma postura de estudo de caso, logo, dando margem a um método experimental baseado em hipóteses e afazeres, empregando os possíveis fatores e as variáveis que se referem ao contexto observado. 
O desenvolvimento das indagações que pautam esta pesquisa se processa no espaço escolar de uma Amazônia edificada por múltiplos territórios, os quais estão fortemente atrelados aos ambientes construídos pelos diferentes grupos humanos que neles vivem e fazem deles seu abrigo e, em muitas situações, lidando com os desafios de introdução a uma nova lógica econômica no território. Santos (1999) ressalta a importância de considerar o mister de extensão em que o sujeito está inserido, uma vez que:

O território não é apenas o conjunto dos sistemas naturais e de sistemas de coisas superpostas. O território tem que ser entendido como o território usado, não o território em si. O território usado é o chão mais a identidade. A identidade é o sentimento de pertencer àquilo que nos pertence. O território é o fundamento do trabalho, o lugar da residência, das trocas materiais e espirituais e do exercício da vida. (SANTOS, 1999, p. 7)

Por conseguinte, cabe situar primeiramente a região: o município de Juruti no estado do Pará. A cidade de Juruti está localizada a aproximadamente $850 \mathrm{~km}$ da capital do estado do Pará e, para fins administrativos e de organização do serviço público, foi dividido pela Lei $\mathrm{n}^{\circ}$ 996/2010, de 15 de setembro de 2010, em quatro distritos administrativos: Tabatinga, Castanhal, Distrito-Sede e Distrito de Marapinima, a principal referência política e econômica constituída de 50 comunidades de caráter tradicional, onde faz parte a comunidade, local/espaço pesquisado.

As comunidades estão inseridas no atual Projeto de Assentamento Extrativista (PAE) em Juruti Velho (área rural), criado em 30 de agosto de 2009. Juruti estadeia como a única cidade brasileira que possui uma lei municipal de manejo de quelônios, criada em dezembro de 2013. Porém, o trabalho com a espécie ocorre desde 2008, entregando aos rios e lagos da região mais de 170 mil quelônios. Conquistas inéditas para Juruti, no Baixo Amazonas, contrapondo-se ao mesmo tempo à existência do empreendimento de extração mineral desenvolvida pela Alcoa (Aluminum Company of America). As situações de disputa e de 
definição de território no contexto jurutiense entre a questão ambiental e o desenvolvimento de grande negócio definem a unidade territorial atual dessa região.

[...] quando o governo brasileiro incentivou a entrada de empresas estrangeiras na Amazônia, a exemplo da norte-americana Reynolds Metals, interessada na exploração mineral da região. Nos anos 2000, a empresa Alcoa sucedeu à Reynolds Metals, instalando-se efetivamente nesse município para explorar bauxita no entorno do Lago Grande de Juruti Velho, onde vivem cerca de 50 comunidades. A implantação da mineradora deu início a uma série de acontecimentos impactantes para o modo de vida local, culminando em uma intensa mobilização coletiva. Esse fato levou o Ministério Público do Estado do Pará (MPE-PA) a tomar medidas judiciais e extrajudiciais com o intuito de reparar danos decorrentes da ação da empresa. (DEMEDA; DE CARVALHO, 2018, p. 6)

Nesse contexto, por habituais constatações de problemáticas ambientais e socioculturais que resultou no surgimento em 2004 da Associação das Comunidades da Região de Juruti Velho (Acorjuve), representando o interesse de 50 comunidades, tencionando resguardar os direitos dos comunitários atingidos pelos impactos decorrentes do empreendimento estrangeiro e que, conforme reporta Silva (2014), a instalação da empresa em Juruti significou a entrada em operação de uma atividade minerária com alta capacidade de alteração das características físicas, sociais, econômicas e ambientais do município. As atividades de exploração da Alcoa constantemente entram em conflito com o modo de vida dos habitantes locais.

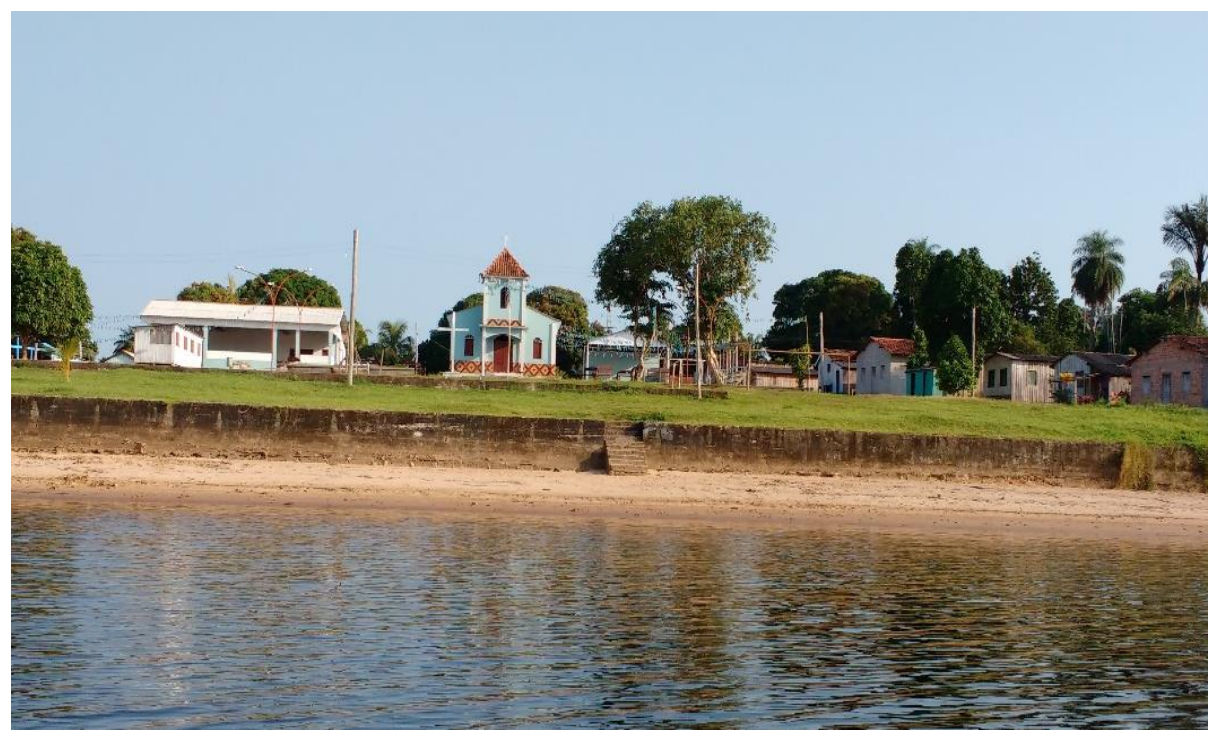

Figura 2. Comunidade na qual a Escola pesquisada está inserida Fonte: Pereira (2019) 
Esse cenário alcança a paleta de realidade da escola pesquisada, em uma comunidade ribeirinha que possui ao todo 98 famílias que vivem do agroextrativismo (atividade pesqueira, coleta de sementes, frutas, produção e consumo de farinha e outros), fazendo parte da região caracterizada pelo pesquisador Lindomar Silva em "Natureza capitalista versus natureza orgânica: o advento da Alcoa e a mobilização e organização das comunidades de Juruti no Baixo Amazonas", de (2014), reforça a percepção desse espaço amazônico paraense como um conjunto de população jurutiense pautada na mobilização de manter seu coletivo tradicional de vida sustentável, ação fundamental para tentar conviver com a empresa a qual faz a exploração de minérios.

\section{RESULTADOS}

A comunidade pesquisada pertence a uma das muitas típicas escolas do campo, geograficamente descritas como ribeirinhas. Os meios de acesso a tais escolas são diferenciados, a maioria das vezes por rios. Há algumas localidades sem energia elétrica por rede de distribuição, funcionando ainda por motores a diesel, que dirá internet! Trata-se de um cenário de grandes desafios, mas aconchegante para todos que ali vivem.

Todos os 13 professores da escola, com idade entre 25 e 45 anos, participaram do projeto. Esses professores ministram aulas de Língua Portuguesa, Matemática, História e Geografia, Ensino Religioso e Artes, Estudos Amazônicos e Língua Inglesa. Foram selecionados com base no interesse em compor um grupo para responder o questionário anônimo e participar da roda de conversa.

Quadro 1. Formação dos professores pesquisados.

\begin{tabular}{|l|}
\hline 10 professores com especialização \\
\hline 2 professores com ensino superior \\
\hline 1 professor com ensino superior incompleto \\
\hline
\end{tabular}

Fonte: Pereira (2019) 
O quadro 1 aponta que a escola do campo, localizada em uma comunidade ribeirinha, conta com um bom quantitativo de professores com especialização (10/13). Segundo os docentes, esse quantitativo de professores especialistas deve-se à participação desse professorado no Programa Nacional de Formação de Professores da Educação Básica (PARFOR): política pública executada na Amazônia para formação de profissionais da educação. Essa política é positiva, sobretudo se comparada às atinentes à formação docente no campo das TDIC na região amazônica, as quais têm sido historicamente imbricadas a descontinuidades de modo a impor sanções à região pela sua peculiaridade geográfica.

Quando perguntados sobre os sites e/ou espaços virtuais que conheciam e utilizavam, os professores relataram familiaridade com redes sociais digitais, como o Facebook, e utilização de vídeos do Youtube. Mas foram poucos os professores, somente dois (2), que indicaram conhecer o Portal do Professor e saber sobre as demais plataformas que disponibilizam objetos de aprendizagem e outros materiais educacionais. Contudo, todos foram unânimes em indicar que no percurso de suas disciplinas tinham o hábito de pesquisar materiais, como vídeos, jogos, imagens, animações, textos e arquivos de som disponíveis na internet. Os relatos evidenciam que os professores buscam na internet recursos para usar em sala de aula. Todavia, é preciso atentar para os materiais disponíveis que são gratuitos e abertos para uso de maneira a permitir uso e reuso, caso contrário, os professores poderão infringir a Lei de Direitos Autorais. É nesse contexto que emerge a necessidade de explanar aos professores sobre a existência de plataformas dedicadas a hospedar os REA.

Quadro 2. Motivos para buscar recursos na internet.

\begin{tabular}{|l|}
\hline 7 professores, por estarem inseridos no objetivo do Projeto Político-Pedagógico \\
\hline 4 professores usam por motivação própria \\
\hline 2 professores usam para incentivar a interação dos grupos de professores. \\
\hline
\end{tabular}

Fonte: Pereira (2019)

A maioria dos professores relata a influência da convivência organizacional junto à gestão/coordenação pedagógica e do Projeto Político Pedagógico (PPP) da escola para que 
eles busquem materiais educacionais no ciberespaço. Tais relatos convergem com o entendimento de Veiga (1998), sobre a escola precisar ter clareza do contexto sociopolítico, econômico e cultural no qual está inserida, o estado de conhecimento do contexto e a escolha dos procedimentos metodológicos e recursos didáticos que melhor atendam às necessidades de aprendizagem, pois:

[...] a escola tem que pensar o que pretende, do ponto de vista político e pedagógico. Há um alvo por ser atingido pela escola: a produção e a socialização do conhecimento, das ciências, das letras, das artes, da política e da tecnologia, para que o aluno possa compreender a realidade socioeconômica, política e cultural, tornando-se capaz de participar do processo de construção da sociedade (VEIGA, 1998, p.25)

Professores rodeados por alguns artefatos tecnológicos, como seus computadores pessoais, celulares, como citaram, sem terem a certeza de algumas funcionalidades desses dispositivos demonstram a demanda por apropriação da cultura digital. A premissa de que a cultura digital deve ser vista como algo vivo que se movimenta e se atualiza constantemente chama atenção para se "pensar a cultura digital como um 'repertório compartilhado' (de signos e significados, práticas, valores, costumes ou qualquer outra coisa), delimitado por algum critério [...] e tão somente uma manobra analítica" (BUZATO, 2010, p. 71).

O grupo não demostrava estar alheio a oportunidades que os favoreçam no desenvolvimento e conhecimento a partir do acesso às TDIC. Ao serem solicitados a definir em palavras o entendimento acerca do uso das TDIC na educação, obteve-se o seguinte panorama:

Gráfico 1. Incidência de palavras sobre o que entendem por tecnologia na educação

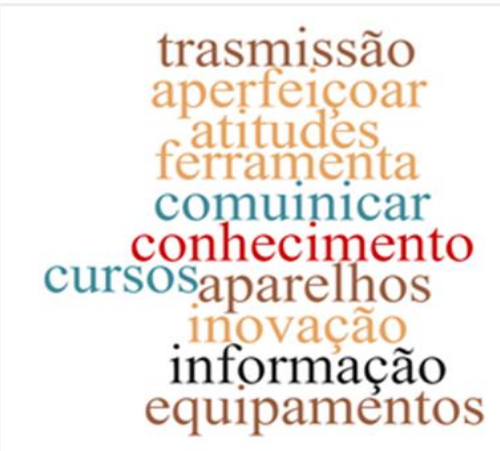

trasmissão

aperfeicoar

ferramenta

comuinicar

conhecimento

ingrã̃o

informação

equipaméntos

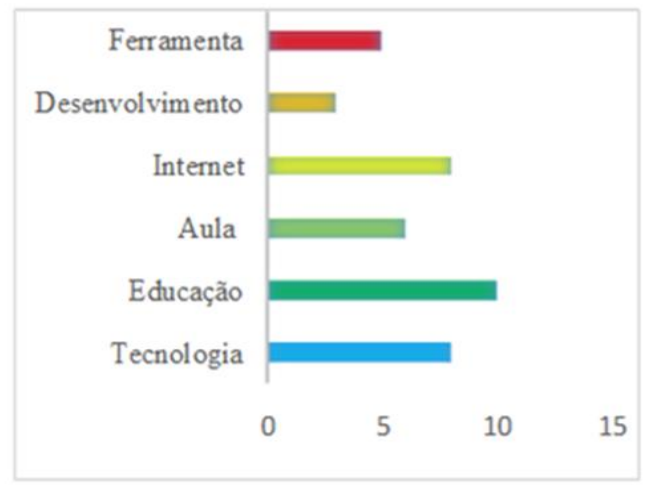


Os professores utilizam o jargão "ferramenta" ao se referirem às TDIC na educação. Quanto a tal representação social, destaca-se o alerta de Padilha e Martinelli (2005) de que a crença no consenso de que os aparatos tecnológicos sejam ferramentas pode se desdobrar na adoção de propostas pedagógicas que usam "ferramentas tecnológicas" de forma reducionista. Para Kenski (2003), a visão de tecnologias como simples ferramentas, apesar de redutora, está extremamente impregnada ao imaginário social. Nesse caso, a tecnologia é compreendida como um recurso facilitador que se materializa normalmente nas máquinas. Assim, a tecnologia torna-se algo materializado com a função de facilitar as atividades cotidianas dos indivíduos. O docente, sem conhecimentos atualizados sobre TDIC, pode trazer para o cenário da cibercultura velhas práticas de mediação da aprendizagem.

Contudo, não se limitando a essa discussão, concorda-se que tais visões do ecossistema educacional decorrem da falta de formação para construção de conhecimento, uma questão de exercício reflexivo, pois passa muito mais por questões pedagógicas do que tecnológicas.

Quando indagados se conheciam REA, para apresentar-lhes alternativas educacionais no âmbito da cultura digital, alguns se identificaram com a opção "Já ouvi falar, mas não sei do que se trata" e outros se identificavam com a opção "não conheço", conforme demonstrado no gráfico 2 .

Gráfico 2. Conhecimento sobre REA

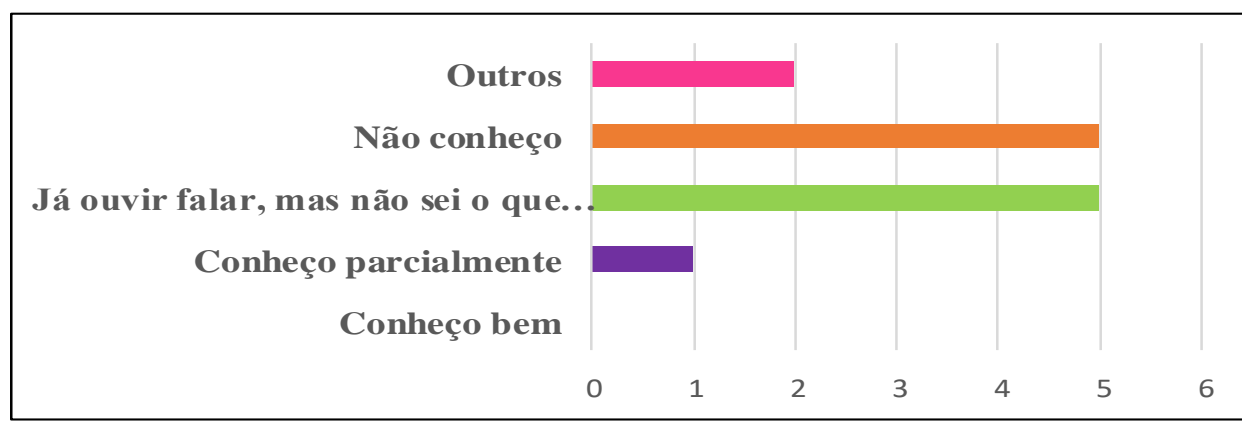

Fonte: Pereira (2019) 
A primeira opção advém de professores que participaram da ação formativa em 2013. Houve um professor que respondeu conhecer parcialmente. No grupo da segunda opção, "não conheço", estavam os docentes que participaram de outras formações e os que não haviam participado de qualquer formação.

As respostas dos professores à busca de temas atuais e de propostas de atividades alinhadas à realidade do campo em que a escola ribeirinha se insere remetem ao anunciado por Pretto (2012), para quem a reflexão sobre a necessidade de compreender que os REA precisam ir muito além do livre compartilhamento de conteúdo produzidos nos grandes centros privilegiados.

Em relação à fluência digital, o gráfico 3 evidencia que há, ainda, um longo caminho a ser percorrido.

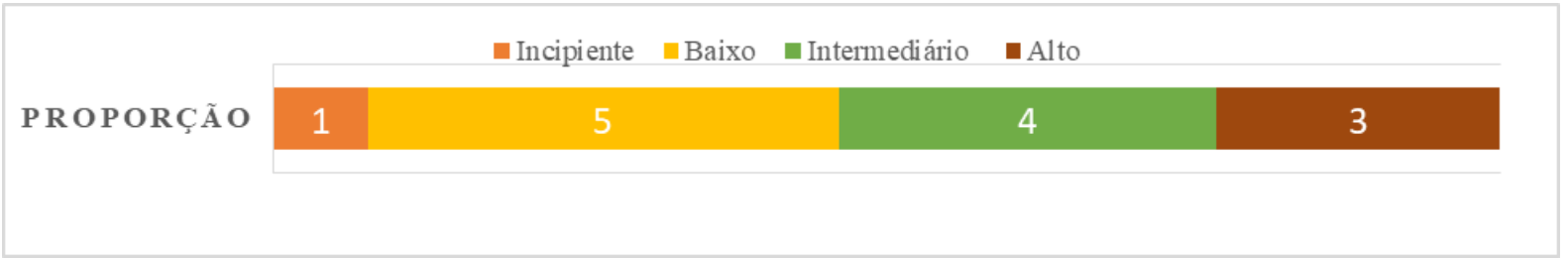

Gráfico 3. Proporção de habilidades com uso das TDIC Fonte: Pereira (2019)

Para Menezes (2010), não se pode cobrar um bom desempenho das escolas, se elas estiverem décadas atrás do que já se tornou trivial nas práticas sociais. A afirmação de Menezes é muito oportuna à realidade de boa parte das escolas ribeirinhas. Há escolas com salas de informática cuja estrutura física aparentemente sustenta a ideia de escola munida de tecnologias, porém, tais salas muitas vezes são subutilizadas e / ou obsoletas, uma vez que os professores, frequentemente, não estão devidamente preparados para utilizar essas tecnologias.

O grupo de professores realiza ações por meio de projetos desenvolvidos no ano eletivo da escola, registrando-as pelo celular, manuseiam editor de slide para apreciação dos resultados pela comunidade escolar. Em meio a tal cenário, concorda-se com Teodoroski (2018) quando 
afirma que para o REA ocorrer a contento, não basta o modelo estar alicerçado na literatura pesquisada dos recursos. É necessária a identificação de características, como produção, armazenamento, disseminação e compartilhamento de materiais e atividades que podem ocorrer de forma assíncrona e vinculada ao cotidiano das práticas sociais de uma dada escola.

A despeito dos desafios relacionados à conexão à internet e à suficiência de computadores na escola, os professores em tela produziram material didático, tornando-se atores e autores dos conteúdos didáticos por eles desenvolvidos. Isso enaltece a escola como um espaço de criação e não de mera reprodução do conhecimento produzido nos grandes centros privilegiados (PRETTO, 2012).

Posto isso, o que se propõe é que as ações formativas voltadas à integração das TDIC às práticas escolares busquem ir além das proposições teóricas para mobilizar os professores em formação a utilizar as TDIC, em geral, e os REA, em particular, de modo autoral e coautoral. Esse movimento formativo caminha em direção a dar representatividade aos olhares das culturas locais em diálogo com os saberes produzidos nos grandes centros (PRETTO, 2012).

\section{CONSIDERAÇÕES E PERSPECTIVAS}

Acredita-se que o caráter inovador das tecnologias no contexto da educação não se restrinja aos recursos de última geração dos equipamentos e dos programas utilizados. A inovação proposta pelo uso autoral e coautoral dos REA abrange, primeiramente, a relação humana estabelecida em torno da utilização dos dispositivos que a escola possui, estimulando estratégias para produzir e difundir conhecimento.

Os princípios de proteção da liberdade, criação e recriação inerentes ao movimento REA incentivam lançar e analisar as apropriações tecnológicas críticas contextualizadas e 
colaborativas no ensino e na aprendizagem, de forma a contribuir para o desenvolvimento e a melhoria da educação básica nas escolas do campo, de modo geral, e as ribeirinhas, em particular. Para favorecer experiências educativas com uso dos REA, programas oriundos de políticas públicas de inclusão digital, como o Programa Nacional de Tecnologia Educacional (ProInfo), distribuíram material digital seguindo a filosofia dos softwares livres. Contudo, é oportuno destacar que, apesar de tais iniciativas, ainda temos que superar a cultura do laboratório de informática atestada com o ProInfo.

Além de se alinharem aos desafios educacionais na região, por convergir com a pedagogia de compartilhamento e com a cultura maker (PADILHA e MARTINELLI, 2015), os REA são elementos passíveis de favorecer o acesso a um maior número de pessoas no imenso território paraense. Em complemento à democratização do acesso, os REA alinham-se com a premissa de integração das TDIC na educação a serviço do desenvolvimento humano, pela potência e fazer trazer à tona experiências coletivas, sociais, servindo, assim, como sensores da realidade regional. Essa perspectiva ampliada de uso dos REA, que não se restringe à aprendizagem de conteúdos de ensino, demanda uma postura "técnica e política" por contribuir para o desenvolvimento de ações políticas em rede, em movimentos indígenas, juvenis, docentes etc. Tal perspectiva de utilização dos REA revela a complexidade e a amplitude das perspectivas políticas no ciberespaço, rearticulando as especificidades regionais e estimulando novos olhares e reflexões.

Todavia, para que isso aconteça, há necessidade de estruturação do espaço escolar com uso das TDIC, levando em consideração as condições materiais da escola, bem como o caráter ideológico inerente a tais tecnologias. A convergência das TDIC na educação provoca o estudo dos movimentos emergentes, como a pedagogia de compartilhamento pela via dos REA. As práticas pedagógicas compartilhadas suportadas pelos REA parecem ser convergentes com a construção de estratégias educacionais dialógicas, autorais e coautorais, apoiadas no ciclo vital de REA - reter, reusar, recombinar, rever e redistribuir - os $\mathbf{5 R}$. 
Por fim, os autores do presente artigo advogam em favor de atitudes formativas que valorizem os saberes locais, valendo-se de rádios escolares ou comunitárias em diálogo com conhecimentos produzidos em outros contextos e que os REA possam ser utilizados por professores e estudantes para pesquisar materiais e serem capazes de copiar, remixar e colocar suas autorias em rede, em um ecossistema de experiências. Nesse movimento, os REA podem mobilizar o intercâmbio de vivências e de materiais didáticos como, por exemplo, entre um professor do estado do Maranhão e um colega do estado do Pará, contribuindo com suas experiências, remixando informações e ampliando conhecimento. Nesse sentido, os REA se consubstanciam como dispositivos tecnológicos de apoio a práticas autorais e coautorais por possibilitar a construção de saberes locais no diálogo profícuo com saberes advindos dos grandes centros privilegiados (PRETTO, 2012), sem estabelecer com eles uma relação de subserviência. Aí incide o particular valor dos REA, em prol de uma educação humanista e emancipadora (FREIRE, 1984).

\section{REFERÊNCIAS}

BONILLA, Maria Helena Silveira. Escola aprendente: para além da sociedade da informação. Rio de Janeiro: Quartet, 2005.

BONILLA, Maria Helena. Políticas públicas para inclusão digital nas escolas. Motrivivência, ano XXII, n. 34, p. 40-60, jun. 2010.

BONILLA, Maria Helena Silveira; OLIVEIRA, Paulo Cezar Souza de. Inclusão Digital: ambiguidades em curso. In.: SILVEIRA, BONILLA, Maria Helena Silveira; PRETTO, Nelson De Luca (Orgs.). Inclusão digital: polêmica contemporânea. Salvador: EDUFBA, v. 2, p. 23-48, 2011.

BUZATO, Marcelo El K. Novos letramentos e apropriação tecnológica: conciliando heterogeneidade, cidadania e inovação em rede. In: RIBEIRO, A. E. (Org.). Linguagem, tecnologia e educação. São Paulo: Petrópolis, 2010.

CASTELLS, Manuel. A sociedade em rede. 9ª ed. São Paulo: Paz e Terra, 2007. 
DEMEDA, Kátia; DE CARVALHO, Luciana Gonçalves. Os royalties da mineração e o sistema da dádiva em Juruti Velho-Juruti, Pará. 2018. Disponível em: < https://periodicos.ufpa.br/index.php/pnaea/article/view/9180>. Acesso em: 29 ago.2020.

FAGUNDES, Lea. Estamos vivendo uma mudança cultural revolucionária. Homenagem à pesquisadora, por ocasião dos 11 anos da Associação Software Livre.Org. 2014. Disponível em: < http://softwarelivre.org/portal/noticias/\%E2\%80\%9Cestamos-vivendo-uma-mudancacultural-revolucionaria\% E2\%80\%9D-diz-lea-fagundes-no-aniversario-da-asl.org>. Acesso em: 28 ago. 2020.

FETTERMANN, Joyce Vieira. Recursos Educacionais Abertos na formação do professorautor: reflexões teóricas. LINKSCIENCEPLACE-Interdisciplinary Scientific Journal, v. 1, n. $2,2014$.

FREIRE, Paulo. A máquina está a serviço de quem? Revista BITS, São Paulo, v. 1, n. 7, p. 6, mai. 1984.

KENSKI, Vani M. (2003). Aprendizagem mediada pela tecnologia. Revista Diálogo Educacional, 4(10), 47-56. Disponível em: http://www2.pucpr.br/reol/pb/index.php/dialogo?dd1=786\&dd99=view\&dd98=pb >. Acesso em: 29 ago. 2020.

LÜDKE, Menga, ANDRÉ, Marli E.D.A. Pesquisa em Educação: abordagens qualitativas. São Paulo: EPU, 1986.

MENESES, Luís Carlos de. Ensinar com a ajuda da tecnologia. Revista Nova Escola. São Paulo, Ano XXV, nº 235, set. 2010, p. 122.

MOURA, Ricardo Damasceno. Inclusão digital e a busca por um acesso tecnológico respaldado nos reais interesses dos povos da Amazônia. Revista de ciência, tecnologia e inovação do estado do Pará, p. 50, 2012.

PADILHA, Márcia; MARTINELLI, Adriana. Cultura maker na escola: por que faz sentido. 16 nov. 2015. Disponível em: < http://www.arede.inf.br/cultura-maker-naescola-por-que-fazsentido/ > Acesso: 26 ago. 2020.

PEREIRA, Ana Pâmela Guimarães. Recursos Educacionais Abertos: contextualização da tecnologia da informação e comunicação em uma escola na comunidade ribeirinha do município de Juriti, Pará. Dissertação. Mestrado em Educação. Universidade Federal do Oeste do Pará, 2019. 
PESCE, Lucila. A Potência Didática dos Recursos Educacionais Abertos para a Docência na Contemporaneidade. Revista Eletrônica de Educação, v. 7, n. 2, p. 195-210, 2013. Disponívelem: $<$ https://www.researchgate.net/publication/270527837_A_POTENCIA_DIDA TICA_DOS_RECURSOS_EDUCACIONAIS_ABERTOS_PARA_A_DOCENCIA_NA_CO NTEMPORANEIDADE>. Acesso: 26 ago. 2020.

PRETTO, Nelson De Luca. Professores universitários em rede: um jeito hacker de ser. Motrivivência, n. 34, p. 156-169, 2010. Disponível em:< https://periodicos.ufsc.br/index.php/motrivivencia/article/view/16038>. Acesso: 26 ago. 2020.

PRETTO, Nelson De Luca. Professores-autores em rede. In: SANTANA, B. et al. Recursos Educacionais Abertos: práticas colaborativas e políticas públicas. Salvador: Edufba, 2012. p. 91-108.

SANTANA, Bianca; ROSSINI, Carolina; PRETTO, Nelson De Luca. Recursos Educacionais Abertos: práticas colaborativas políticas públicas. 1 imp. Salvador: EDUFBA. 2012.

SANTOS, Milton. Território e dinheiro. In: Revista GEOgraphia. Niterói: programa de PósGraduação em Geografia - PPGEO - UFF/AGB, v.1, n1. p. 7 a 13, 1999.

SILVA, Lindomar de Jesus de Sousa. Natureza capitalista versus natureza orgânica: o advento da ALCOA e a mobilização e organização das comunidades de Juruti no Baixo Amazonas / Lindomar de Jesus de Sousa Silva; Orientador, Maurílio de Abreu Monteiro. 2014.

TEODOROSKI, Rita de Cassia Clark et al. Recursos educacionais abertos (REA) no Brasil: construção de um modelo ecossistema de REA. 2018.

VEIGA, Zilah de Passos Alencastro. As instâncias colegiadas da escola. In: Veiga Ilma P. e RESENDE, Lucia M. G. de (orgs). Escola: espaço do projeto político pedagógico. Campinas: Papirus, 1998.

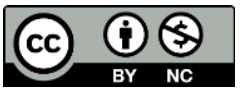

Este é um artigo de acesso aberto distribuído sob os termos da Licença Creative Commons Atribuição Não Comercial-Compartilha Igual (CC BYNC- 4.0), que permite uso, distribuição e reprodução para fins não comerciais, com a citação dos autores e da fonte original e sob a mesma licença. 